\title{
Prevalence and associated factors of $T$-score discordance between different sites in Iranian patients with spinal cord injury
}

\author{
SA Alavizadeh ${ }^{1}$, MR Mohajeri-Tehrani ${ }^{1}$, A Rostamian $^{2}$, HR Aghaei Meybodi ${ }^{3}$, M Qorbani $^{4,5}$, AA Keshtkar ${ }^{6}$, \\ SS Panahi ${ }^{7}$, F Rahdari ${ }^{8}$ and P Khashayar ${ }^{6}$
}

Objectives: The present study was conducted to determine the prevalence of $T$-score discordance and its risk factors in a group of patients with spinal cord injury in a university teaching hospital in the Iranian capital of Tehran.

Methods: This cross-sectional study was conducted on paraplegic men undergoing bone density testing in an outpatient clinic at a hospital in the Iranian capital, Tehran, between March 2011 and 2012. A questionnaire on demographic and anthropometric characteristics, including age, height, weight, engagement in physical activity and personal smoking habits, was filled out for each subject. All the subjects underwent bone mineral density measurement and blood samples were sent for laboratory testing.

Results: Major T-score discordance between two sites was noted in 54 (41.22\%) patients. Multivariate logistic regression revealed that every unit increase in serum calcium levels, as the only factor influencing T-score discordance, was associated with a 2.49-fold increased risk in T-score discordance in the area. As for the spine and radius, BMI was the only influencing factor as every unit increase in BMI was associated with a 14\% lower risk for T-score discordance in these regions. Body mass index was the only factor, based on the multivariate model, affecting the risk of developing T-score discordance between two sites.

Conclusion: Our study revealed the high prevalence of $T$-score discordance in patients with spinal cord injury. Physicians should therefore be encouraged to perform BMD at three sites when visiting patients with such injuries.

Spinal Cord (2014) 52, 322-326; doi:10.1038/sc.2013.143; published online 3 December 2013

Keywords: osteoporosis; T-score discordance; spinal cord injury; bone mineral density

\section{INTRODUCTION}

Recent studies show that every year about 12000 new cases of spinal cord injury (SCI) occur in the United States, and as a result the prevalence of the condition has increased from 207000 cases in 1994 to 270000 in $2012 .{ }^{1}$ This increasing trend could be due to the improved treatment modalities and thus increased lifespan in these patients. From among the many morbidities reported in these individuals, reduced bone mass and, consequently, increased fracture risk are of great importance. ${ }^{2}$ Many studies have reported that more than $75 \%$ of these patients suffer from low bone mass or osteoporosis. ${ }^{3}$ Moreover, about $50 \%$ of them may experience at least one fragility fracture in their life. ${ }^{4} \mathrm{~A}$ recent study based on Northwest Regional Spinal Cord Injury System (NWRSCIS) SCI Forum Reports showed that about $14 \%$ of patients with SCI experience a fracture in the first 10 years after the accident. ${ }^{5,6}$

Although bone production reaches its normal rate within 2 weeks after injury, studies have shown that bone mineral density (BMD) is reduced by $4 \%$ every month thereafter; the amount is reported to reach about $40 \%$ within 2 years. ${ }^{7}$ Many studies have reported that bone loss in patients with SCI reaches a plateau within 3 to 5 years. ${ }^{8-10}$ Others, however, believe that more time is needed before the bone production-absorption balance is reachieved in these patients. ${ }^{11,12}$

This bone loss is different from what happens during a normal aging process and is mainly because of particular mechanical, neurovascular and hormonal changes that occur in these patients. ${ }^{13,14}$ In these patients, bone loss happens at a greater pace in trabecular bones and at levels lower than that in cord injury, resulting in $T$-score discordance. ${ }^{15-17} T$-score is a statistical definition indicating the difference between patient's BMD and that of the normal population in the age group of 20-30 years (reference population). According to the literature, major $T$-score discordance is reported in $2.7-4.3 \%$ of cases, whereas minor discordance is more common and reported in as high as $35-41 \%$ of the population..$^{18}$ Considering the high prevalence of the condition, $T$-score discordance might be troublesome for the physicians and may result in negative outcomes in the patients, as a true osteoporotic patient must not go

${ }^{1}$ Endocrinology and Metabolism Research Center, Endocrinology and Metabolism Clinical Sciences Institute, Tehran University of Medical Sciences, Tehran, Iran; ${ }^{2}$ Rheumatology Department, Imam Khomeini Hospital, Tehran University of Medical Sciences, Tehran, Iran; ${ }^{3}$ Endocrinology and Metabolism Research Center, Endocrinology and Metabolism Research Institute, Tehran University of Medical Sciences, Tehran, Iran; ${ }^{4}$ Department of Public Health, Alborz University of Medical Sciences, Karaj, Iran; ${ }^{5}$ Department of Epidemiology, Iran University of Medical Sciences, Tehran, Iran; ${ }^{6}$ Osteoporosis Research Center, Endocrinology and Metabolism Clinical Sciences Institute, Tehran University of Medical Sciences, Tehran, Iran; ${ }^{7}$ Rheumatology Department, Khatamolanbia Hospital, Shahed University of Medical Sciences, Tehran, Iran and ${ }^{8}$ Brain and Spinal Injury Research Center, Tehran University of Medical Sciences, Tehran, Iran

Correspondence: Dr MR Mohajeri-Tehrani, EMRC, Shariati Hospital, Kargar Street, Tehran 14114, Iran.

E-mail: mrmohajeri@tums.ac.ir

or Dr A Rostamian, Rheumatology Department, Imam Khomeini Hospital, Tehran University of Medical Sciences, Tehran, Iran.

E-mail: arostamian@tums.ac.ir

Received 4 June 2013; revised 12 September 2013; accepted 18 October 2013; published online 3 December 2013 
undiagnosed and a healthy patient must not be falsely diagnosed as osteoporotic.

There is no available guideline for the diagnosis and treatment of osteoporosis in SCI patients. ${ }^{19}$ Moreover, diagnosing osteoporosis and determining the threshold for fractures in this population based on BMD measured by dual-energy X-ray absorptiometry still pose a challenge. $^{20,21}$ Given these conditions, having more detailed information about the bone loss rate and the pattern of $T$-score discordance in these patients could be useful. As a result, we attempted to determine the prevalence of $T$-score discordance and its risk factors in a group of SCI patients in the Iranian capital of Tehran.

\section{MATERIALS AND METHODS}

This cross-sectional study was conducted on paraplegic men undergoing bone density testing in an outpatient clinic at a university teaching hospital in Tehran between March 2011 and 2012. The study was approved by the Ethical board Committee of the Endocrinology and Metabolism Research Institute.

Those with mental problems interfering with the interview process or suffering from acute or chronic renal failure $(\mathrm{Cr}>1.5)$, advanced liver failure or any type of cancer and those who had received any amount of vitamin D or any corticosteroid equal to $5 \mathrm{mg}$ prednisolone during the past 6 months were excluded. All patients signed a written informed consent form.

A questionnaire on the demographic and anthropometric characteristics, including age, height, weight, engagement in physical activity and personal smoking habits, was filled out for each subject. Body Mass Index (BMI) was calculated by dividing weight by the square of height.

All subjects underwent BMD measurement using dual-energy X-ray absorptiometry (Hologic Inc., Waltham, MA, USA) at three skeletal regions (sites): lumbar spine, radius and hip. The measurement was taken by a single expert technician and was based on the manufacturer's protocol. The accuracy of the instrument was tested each time using a special phantom. Except for those having a fixation or similar prostheses, BMD was measured at total hip, L1-L4 and radius of the non-dominant hand in all patients.

The patients were classified into two groups: under 50 and over 50 years. Those aged over 50 years were classified as normal $(T$-score $>-1)$, as having osteopenia $(-1 \leqslant T$-score $\leqslant-2.5)$ or as having osteoporosis $(T$-score $>-2.5)$ on the basis of the World Health Organization classification. ${ }^{22}$ In those aged $<50$ years, $Z$-scores $\leqslant-2$ were considered as low bone mass, whereas other scores were considered normal.

$T$-score discordance is observed when the difference between two studied sites is sufficient to result in the two measurement sites falling into two different diagnoses as defined by the World Health Organization classification system. T-score discordance can be minor or major. Minor discordance is defined as being present when the difference between the two sites is no more than one World Health Organization diagnostic class. Major discordance is defined as present when one site is osteoporotic and the other site is normal. ${ }^{23}$

As for laboratory testing, $5 \mathrm{~cm}^{3}$ venous blood samples were collected in polystyrene test tubes with a skirt cap and immediately sent to the Khatamolanbia Laboratory (Tehran, Iran). Calcium (Ca) and phosphorous (P) (Man), alkaline phosphatase (Alk-ph) and parathormone (PTH) (IDS Kit, IDS, London, UK), luteinizing hormone (LH) and follicle-stimulating hormone (FSH) (Roche Diagnostics GmbH, Mannheim, Germany), thyroidstimulating hormone (TSH), sex hormone-binding globulin (SHBG) and T3 and T4 (Monobind, Lake Forest, CA, USA) were assessed in each patient.

The gathered data were analyzed using SPSS ver. 16 (SPSS, Armonk, NY, USA). Mean and standard deviation along with percentage and frequency was used to describe demographic and anthropometric variables. Logistic regression was used to assess factors influencing $T$-score discordance. In this regard, variables with $P$-value $<0.2$ in the univariate logistic regression were taken into account in the stepwise multivariate logistic regression. $P$-values $<0.05$ were considered significant.

\section{RESULTS}

A total of 170 paraplegic male subjects with a mean age of $47.45 \pm 6.79$ years were recruited. Among them, 118 (69.4\%) were aged $<50$ years, of whom $65.6 \%$ had injury at the thoracic level and $34.4 \%$ at the lumbar level. About $51.2 \%$ of the injuries were complete. Nearly $94.6 \%$ of them were wheelchair bound, whereas $5.4 \%$ could walk using help.

Table 1 outlines the anthropometric characteristics of these patients. Eleven $(6.5 \%)$ of them were underweight, whereas 61 $(35.9 \%)$ and $15(8.8 \%)$ were overweight and obese, respectively. Fifty-one $(30 \%)$ patients were reported not to be engaged in any kind of physical activity. In the majority of the others, physical activity was confined to a single 1-h session per week (Table 1). Osteoporosis at any two sites was reported in $104(61.2 \%)$ patients. Table 2 shows the prevalence of osteoporosis at the three studied sites separately. Major $T$-score discordance between two sites was noted in $54(41.22 \%)$ patients (Table 3 ). The majority of $T$-score discordance was reported between the scores measured at the hip and radius.

The results of uni- and multivariate logistic regression of T-score discordance between different sites are shown in Tables 4 and 5 . In each area, variables with $P$-value $<0.2$ in the univariate logistic regression were entered in the multivariate logistic regression model. Multivariate logistic regression revealed that in the lumbar spine and

Table 1 The anthropometric characteristics and the personal habits of the studied population

\begin{tabular}{lr}
\hline Mean height $(\mathrm{cm})$ & $171.92 \pm 6.99$ \\
Mean weight $(\mathrm{Kg})$ & $72.75 \pm 13.7$ \\
Mean BMI $\left(\mathrm{kg} \mathrm{m}^{-2}\right)$ & $24.59 \pm 4.25$ \\
Physical activity & $2(1.2 \%)$ \\
$\quad$ Athletic exercise & $117(98.8 \%)$ \\
Any type of exercise & \\
Cigarette smoking & \\
$\quad$ Smoker & $23(13.5)$ \\
Ex-smoker & $13(7.6)$ \\
Non-smoker & $134(78.8)$
\end{tabular}

Abbreviation: BMI, body mass index.

Table 2 The severity of osteoporosis at the three studied sites (N(\%))

\begin{tabular}{llcrr}
\hline & Age group (years) $(\mathrm{n})$ & Osteoporosis & Osteopenia & Normal \\
\hline L1-L4 & $<50(107)$ & $17(14.4)$ & $24(20.3)$ & $66(55.9)$ \\
& $>50(44)$ & $5(9.6)$ & $8(15.4)$ & $31(59.6)$ \\
Total hip & $<50(114)$ & & & \\
& $>50(49)$ & $21(40.4)$ & $17(32.7)$ & $11(21.2)$ \\
Radius & $<50(106)$ & & & \\
& $>50(45)$ & $7(14.9)$ & $19(16.1)$ & $73(61.9)$ \\
& & & $11(21.2)$ & $27(51.9)$ \\
\hline
\end{tabular}

Table 3 The prevalence of $T$-score discordance at the three studied sites $(N(\%))$

\begin{tabular}{lcccc}
\hline $\begin{array}{l}\text { T-score } \\
\text { discordance }\end{array}$ & $\begin{array}{c}\text { Lumbar } \\
\text { spine-hip }\end{array}$ & $\begin{array}{c}\text { Lumbar } \\
\text { spine-radius }\end{array}$ & Hip-radius & Any two sites \\
\hline Minor & $57(38.9)$ & $40(29.8)$ & $59(40.4)$ & $60(45.80)$ \\
Major & $46(31.2)$ & $20(15)$ & $52(35.6)$ & $54(41.22)$ \\
Total & $103(70.1)$ & $60(44.8)$ & $111(76.0)$ & $114(87)$ \\
\hline
\end{tabular}


Table 4 Correlation of dependent variables with $T$-score discordance at different sites (univariate analysis)

\begin{tabular}{|c|c|c|c|c|}
\hline Variables & $\begin{array}{l}\text { Lumbar and hip } \\
\text { OR }(95 \% \mathrm{Cl})\end{array}$ & $\begin{array}{l}\text { Lumbar and radius } \\
\text { OR }(95 \% \mathrm{Cl})\end{array}$ & $\begin{array}{c}\text { Hip and radius } \\
\text { OR }(95 \% \mathrm{Cl})\end{array}$ & $\begin{array}{l}\text { Three sites } \\
\text { OR }(95 \% \mathrm{Cl})\end{array}$ \\
\hline Age (years) & $0.99(0.94-1.05)$ & $0.99(0.95-1.04)$ & $0.96(0.91-1.01)$ & $0.97(0.91-1.04)$ \\
\hline $\mathrm{BMI}\left(\mathrm{kg} \mathrm{m}^{-2}\right)$ & $0.99(0.91-1.07)$ & $0.87(0.80-0.96)^{a}$ & $0.96(0.87-1.05)$ & $0.87(0.78-0.98)^{a}$ \\
\hline Smoking (per day) & $0.98(0.93-1.03)$ & $0.96(0.90-1.02)$ & $1.00(0.95-1.07)$ & $0.96(0.90-1.03)$ \\
\hline $\mathrm{Ca}(\mathrm{mgdl}-1)$ & $2.12(0.87-5.14)$ & $0.66(0.28-1.53)$ & $1.25(0.49-3.19)$ & $1.94(0.55-6.74)$ \\
\hline$P\left(\mathrm{mg} \mathrm{dl}^{-1}\right)$ & $0.63(0.32-1.21)$ & $0.81(0.43-1.50)$ & $0.77(0.38-1.55)$ & $0.55(0.22-1.37)$ \\
\hline Alk-ph $\left(||^{-1}\right)$ & $1.00(0.99-1.00)$ & $0.99(0.99-1.00)$ & $0.99(0.99-1.00)$ & $0.99(0.99-1.00)$ \\
\hline PTH (pg ml-1) & 0.99 (0.98-1.00) & $1.00(0.99-1.01)$ & 0.99 (0.97-1.00) & $0.99(0.97-1.01)$ \\
\hline $\operatorname{VitD}\left(\mathrm{nmol} \mathrm{I}^{-1}\right)$ & $1.00(0.92-1.02)$ & $0.99(0.97-1.02)$ & 0.99 (0.97-1.02) & 0.99 (0.96-1.03) \\
\hline $\mathrm{LH}\left(\mathrm{mlU} \mathrm{ml}{ }^{-1}\right)$ & $1.06(0.93-1.20)$ & $0.96(0.86-1.08)$ & $0.96(0.85-1.08)$ & $1.03(0.85-1.23)$ \\
\hline $\mathrm{FSH}\left(\mathrm{mlU} \mathrm{ml}^{-1}\right)$ & $0.98(0.95-1.02)$ & $1.01(0.98-1.05)$ & $1.00(0.96-1.04)$ & $1.03(0.94-1.13)$ \\
\hline TSH (mIU ml-1) & $0.99(0.82-1.21)$ & $1.02(0.85-1.23)$ & $1.21(0.88-1.66)$ & $1.24(0.80-1.90)$ \\
\hline Testosterone (ng dl ${ }^{-1}$ ) & $1.00(0.99-1.00)$ & $1.00(0.99-1.00)$ & $0.99(0.99-1.00)$ & $1.00(0.99-1.00)$ \\
\hline SHBG $\left(n m o l I^{-1}\right)$ & $0.98(0.96-1.01)$ & $1.03(1.00-1.06)^{a}$ & $0.99(0.96-1.02)$ & $1.04(0.98-1.09)$ \\
\hline T3 (ngml-1) & $0.57(0.13-1.71)$ & $1.11(0.32-3.82)$ & $0.71(0.28-1.70)$ & $0.19(0.34-1.12)$ \\
\hline T4 $\left(n g \mathrm{ml}^{-1}\right)$ & $0.97(0.79-1.18)$ & $1.14(0.93-1.40)$ & $1.02(0.83-1.26)$ & $1.02(0.76-1.37)$ \\
\hline Urine Ca (mg $\left.24 \mathrm{~h}^{-1}\right)$ & $0.99(0.99-1.00)$ & $1.00(0.99-1.00)$ & $0.99(0.99-1.00)$ & $1.00(0.99-1.00)$ \\
\hline Physical activity & $1.45(0.67-3.12)$ & $0.86(0.40-1.83)$ & $1.13(0.48-2.63)$ & $1.52(0.51-4.49)$ \\
\hline
\end{tabular}

Abbreviations: Alk-ph, alkaline phosphatase; BMI, body mass index; Ca, calcium; FSH, follicle-stimulating hormone; LH, luteinizing hormone; P, phosphorous; PTH, parathormone; SHBG, sex hormone-binding globulin; TSH, thyroid-simulating hormone; VitD, vitamin D.

a $P$-value $<0.05$.

Table 5 Correlation of dependent variables with $T$-score discordance at different sites (multivariate analysis)

\begin{tabular}{|c|c|c|c|c|}
\hline Variables & $\begin{array}{l}\text { Lumbar and hip } \\
\operatorname{Exp} B(95 \% \mathrm{Cl})\end{array}$ & $\begin{array}{l}\text { Lumbar and radius } \\
\operatorname{Exp} B(95 \% \mathrm{Cl})\end{array}$ & $\begin{array}{l}\text { Hip and radius } \\
\text { Exp } B(95 \% \mathrm{Cl})\end{array}$ & $\begin{array}{c}\text { Three sites } \\
\text { Exp } B(95 \% \mathrm{Cl})\end{array}$ \\
\hline Age (years) & - & - & $0.969(0.918-1.022)$ & - \\
\hline $\mathrm{BMI}\left(\mathrm{kg} \mathrm{m}^{-2}\right)$ & - & $0.869(0.791-0.956)^{a}$ & - & $0.877(0.782-0.982)^{a}$ \\
\hline $\mathrm{Ca}\left(\mathrm{mg} \mathrm{dl} \mathrm{l}^{-1}\right)$ & $2.496(0.996-6.253)$ & - & - & - \\
\hline Alk-ph $\left(\mid U^{-1}\right)$ & - & $0.996(0.990-1.001)$ & 0.970 (0.919-1.004) & - \\
\hline PTH $\left(p g \mathrm{ml}^{-1}\right)$ & - & - & $0.990(0.978-1.003)$ & - \\
\hline Testosterone (ng dl ${ }^{-1}$ ) & - & - & $0.998(0.997-1.000)$ & - \\
\hline SHBG $\left(\mathrm{nmol} \mathrm{I}^{-1}\right)$ & - & $1.023(0.992-1.056)$ & - & $1.026(0.969-1.087)$ \\
\hline T3 (ng ml-1) & - & - & - & $0.227(0.037-1.399)$ \\
\hline T4 (ngml-1) & - & $1.210(0.977-1.498)$ & - & - \\
\hline Physical activity & $0.550(0.279-1.087)$ & - & - & $0.542(0.209-1.408)$ \\
\hline
\end{tabular}

Abbreviations: Alk-ph, alkaline phosphatase; BMI, body mass index; Ca, calcium; Cl, confidence interval; PTH, parathormone; SHBG, sex hormone-binding globulin.

a $P$-value $<0.05$

hip only serum calcium was statistically significant, which resulted in every unit increase in serum calcium levels per unit, which was associated with a 2.49-fold increased risk for $T$-score discordance in the spine and radius (95\% confidence interval: 1.01-6.25).

BMI was the only factor, based on the multivariate model, affecting $T$-score discordance between two sites. Every increase in BMI value was associated with a $13 \%$ decrease in $T$-score discordance between two sites.

\section{DISCUSSION}

The present study reported $T$-score discrepancy between the hip and radius in $76 \%$ of the cases (35.6\% major and $40.4 \%$ minor). $T$-score discrepancy between the hip and lumbar spine was also reported in $70.1 \%$ (major in $31.2 \%$ and minor in $38.9 \%$ ) of the patients. In line with previous studies, our research showed a higher rate of $T$-score discrepancy between the hip and lumbar spine in these patients. ${ }^{24}$ This rate was reported to be higher than that reported in the healthy population. ${ }^{33}$
Osteoporosis and osteopenia were reported in $104(61.2 \%)$ and $46(27.2 \%)$ patients in the studied population, which was lower than that reported in a previous study on spinal cord-disabled veterans by Shojaei et al. ${ }^{25}$ This could be attributed to the longer duration of SCI in the veterans studied in the latter research. Similar to previous studies, bone loss was reported to be more severe at the hip. ${ }^{26}$ Although the prevalence of osteoporosis at the spine and wrist was nearly equal in our study, many studies have reported a higher rate of bone loss in the upper extremities of SCI patients. ${ }^{27}$ There have been a few studies reporting a decrease in BMD values of the bones underlying the spinal cord lesion. ${ }^{28}$

Discrepancy could be due to several reasons ranging from physiologic dissimilarities at the skeletal sites, pathophysiologic divergences, differences between BMD machines and technical problems. In SCI patients, a number of factors such as vertebral fractures, lumbar spine degenerative disease, aortic calcification and lumbar spine instrumentation/internal fixation are responsible for the high rate of the condition. 
Physiologic changes are considered the main reason behind the majority of discrepancies reported in this study. Several studies have reported that training programs stressing axial loads of the skeletal system may lead to an increase in BMD in the spine and hip of young individuals. ${ }^{29}$ Prince et al. ${ }^{30}$ similarly showed that a reduction in function and longer immobility have significant negative effects on BMD values in hemiplegic patients following a CVA. In contrast, del Puente et al. ${ }^{31}$ reported that different factors, other than length of immobility, might come into play in determining bone loss in this condition. According to del Puente et al., ${ }^{31}$ the time since menopause was the main predictive factor of bone loss in postmenopausal women. Similarly, Dauty et al. ${ }^{27}$ reported that biomechanical stress had no effect on BMD values as they failed to report any correlation between the daily sitting period and lumbar BMD values or between the daily passive verticalization period and the lower extremity BMD values. ${ }^{27}$ According to their results, the neurological state was the only important factor in this regard.

These findings could explain our findings. Mechanical stimulation of the lumbar spine in paraplegic individuals bound to a wheelchair can improve the function of the osteoblasts, resulting in more bone formation and preventing further bone loss at the lumbar spine. On the other hand, immobility in lower extremities and less force imposed on the hips of these patients may accelerate the bone loss process. In other words, apart from immobility, factors such as age, gender, level of cord injury, muscular spasticity and the duration of injury result in a more rapid bone loss process in certain bones of SCI patients, causing $T$-score discordance. ${ }^{32}$

From among bone-related anthropometric and metabolic variables linked with $T$-score discordance in the present study, BMI was considered a protective factor and serum Ca level as a risk factor. Corresponding to our results, Mounach et al. ${ }^{24}$ and Moayyeri et al., ${ }^{33}$ in two different studies on a healthy population aged over 50 years, reported BMI as the most important factor that correlated with the lower rate of $T$-score discordance. According to their result, age was another factor influencing the $T$-score discordance rate. The nonsignificant correlation between age and $T$-score discordance noted in our study could be attributed to the lower age of our study population or to the nature of bone loss in patients with SCI.

Kaya et $a .^{34}$ in their study on SCI patients correlated serum $\mathrm{P}$ and Alk-ph along with $24 \mathrm{~h}$ urine $\mathrm{Ca}$ levels and urine $\mathrm{Ca}$ to $\mathrm{Cr}$ ratio to the condition. They, however, reported the value to be higher in patients with a longer history of the lesion. ${ }^{26}$ According to the results of this study, no correlation was found between lesion level, muscular spasticity and BMD. Ragnarsson and Sell ${ }^{35}$ supported the results of our study; they found that spasticity had no protective effect on BMD values.

Considering the cross-sectional nature of the study and the fact that the present research was conducted on a group of paraplegic men, the results of this study could not be generalized to all patients with SCI. Our study revealed the high prevalence of $T$-score discordance in patients with SCI. Reduced bone loss at the hip along with low prevalence of osteoporosis/osteopenia at the lumbar spine and radius noted in these patients was the main reason behind the high prevalence of $T$-score discordance in SCI patients compared with the general population.

It could be concluded that the pattern of $T$-score discrepancy in SCI patients is different from that of the healthy population. Considering the results, BMI was the most effective factor in the risk of $T$-score discordance. It should be added that the effects of the level of injury and the duration of the injury on $T$-score discordance were not taken into account in the present study. Further studies are therefore needed to assess the importance of these factors.
Considering the high prevalence of $T$-score discordance in these patients, physicians should be encouraged to perform BMD at three sites when visiting patients with SCI. In other words, measuring multiple sites in these patients may reduce the likelihood of missing an osteoporotic patient. However, there could be increases not only in expense but also in false-positive rates, resulting in some normal subjects receiving treatment.

Although there are technical limitations to acquiring and interpreting dual-energy X-ray absorptiometry results in SCI patients, the technique is still the best examination for assessing bone mass in these individuals. As a result, the best protocol and practical aspects should be defined for this specific population to overcome all these shortcomings.

\section{DATA ARCHIVING}

There were no data to deposit.

\section{CONFLICT OF INTEREST}

The authors declare no conflict of interest.

1 National Spinal Cord Injury Statistical Center. Spinal cord injury facts and figures at a glance. J Spinal Cord Med 2012; 35: 68-69.

2 Coupaud S, McLean AN, Lloyd S, Allan DB. Predicting patient-specific rates of bone loss at fracture-prone sites after spinal cord injury. Disabil Rehabil 2012; 34: 2242-2250.

3 Szollar SM, Martin EM, Sartoris DJ, Parthemore JG, Deftos LJ. Bone mineral density and indexes of bone metabolism in spinal cord injury. Am J Phys Med Rehabil 1998; 77: 28-35.

4 Comarr $\mathrm{AE}$, Hutchinson $\mathrm{RH}$, Hutchinson $\mathrm{RH}$. Bors. Extremity fractures of patients with spinal cord injuries. J Spinal Cord inj Rehabil 2005; 11: 1-10.

5 Northwest Regional Spinal Cord Injury System (NWRSCIS) SCI Forum ReportsAvailable at: http://www.depts.washington.edu/rehab/sci/ms01.html. (February 2012)

6 Morse LR, Giangregorio L, Battaglino RA, Holland R, Craven BC, Stolzmann KL et al. VA-based survey of osteoporosis management in spinal cord injury. PMR 2009; 1 : 240-244.

7 Dauty M, Perrouin Verbe B, Maugars Y, Dubois C, Mathe JF. Supralesional and sublesional bone mineral density in spinal cord-injured patients. Bone 2000; 27 . 305-309.

8 Garland DE, Steward CA, Adkins RH, Hu SS, Rosen C, Liotta FJ et al. Osteoporosis after spinal cord injury. J Orthop Relat Res 1992; 10: 371-378.

9 Eser P, Frotzler A, Zehnder Y, Wick L, Knecht H, Denoth J et al. Relationship between the duration of paralysis and bone structure: a pQCT study of spinal cord injured individuals. Bone 2004; 34: 869-880.

10 Frotzler A, Berger M, Knecht H, Eser P. Bone steady-state is established at reduced bone strength after spinal cord injury: a longitudinal study using peripheral quantitative computed tomography (pQCT). Bone 2008; 43: 549-555.

11 Modlesky CM, Majumdar S, Narasimhan A, Dudley GA. Trabecular bone microarchitecture is deteriorated in men with spinal cord injury. J Bone Miner Res 2004; 19: 48-55.

12 Slade JM, Bickel CS, Modlesky CM, Majumdar S, Dudley GA. Trabecular bone is more deteriorated in spinal cord injured vs estrogen-free postmenopausal women. Osteoporos Int 2005; 16: 263-272.

13 Jiang SD, Dai LY, Jiang LS. Osteoporosis after spinal cord injury. Osteoporos Int 2006; 17: 180-192.

14 Claus-Walker J, Halstead LS. Metabolic and endocrine changes in spinal cord injury: IV. Compounded neurologic dysfunctions. Arch Phys Med Rehabil 1982; 63: 632-638.

15 Uebelhart D, Hartmann D, Vuagnat H, Castanier M, Hachen HJ, Chantraine A. Early modifications of biochemical markers of bone metabolism in spinal cord injury patients. A preliminary study. Scand J Rehabil Med 1994; 26: 197-202.

16 Garland DE, Adkins RH, Stewart CA. Five-year longitudinal bone evaluations in individuals with chronic complete spinal cord injury. J Spinal Cord Med 2008; 31: 543-550.

17 Liu G, Peacock M, Eilam O, Dorulla G, Braunstein E, Johnston CC. Effect of osteoarthritis in the lumbar spine and hip bone mineral density and diagnosis or osteoporosis in elderly men and women. Osteoporos Int 1997; 7: 564-569.

18 El Maghraoui A, Mouinga Abayi DA, Ghozlani I, Mounach A, Nouijai A, Ghazi M. Prevalence and risk factors of discordance in diagnosis of osteoporosis using spine and hip bone densitometry. Ann Rheum Dis 2007; 66: 271-272.

19 Charmetant C, Phaner V, Condemine A, Calmels P. Diagnosis and treatment of osteoporosis in spinal cord injury patients: a literature review. Ann Phys Rehabil Med 2010; 53: 655-668.

20 Gaspar AP, Lazaretti-Castro M, Brandão CMA. Bone mineral density in spinal cord injury: an evaluation of the distal femur. J Osteoporos 2012; 2012: 519754 
21 Bauman WA, Kirshblum S, Cirnigliaro C, Forrest GF, Spungen AM. Underestimation of bone loss of the spine with posterior-anterior dual-energy X-ray absorptiometry in patients with spinal cord injury. J Spinal Cord Med 2010; 33: 214-220.

22 World Health Organization (WHO). Assessment of fracture risk and its application to screening for postmenopausal osteoporosis: report of a WHO study group. WHO Technical Report Series, Report No. 843. WHO: Geneva, Switzerland.

23 Woodson G. Dual X-ray absorptiometry T-score concordance and discordance between the hip and spine measurement sites. J Clin Densitom 2000; 3: 319-324.

24 Mounach A, Abayi DA, Ghazi M, Chozlani I, Nouijai A, Achemlal L et al. Discordance beetween hip and spine bone mineral density measurement using DXA: prevalence and risk factors. Semin Arthritis Rheum 2009; 38: 467-471.

25 Shojaei H, Soroush MR, Modirian E, Gholizadeh H. An evaluation of osteoporosis prevalence in spinal cord disabled veterans. Daneshvar Med 2007; 14: 37-44. (Persian).

26 Tsuzuku S, Ikegami Y, Yabe K. Bone mineral density differences between paraplegic and quadriplegic patients: a cross-sectional study. Spinal Cord 1999; 37: 358-361.

27 Sabo D, Blaich S, Wenz W, Hohmann M, Loew M, Gerner HJ. Osteoporosis in patients with paralysis after spinal cord injury. A cross sectional study in 46 male patients with dual-energy X-ray absorptiometry. Arch Orthop Trauma Surg 2001; 121 75-78.
28 Dauty M, Verbe BP, Maugars Y, Dubois C, Mathe JF. Supralesional and sublesional bone mineral density in spinal cord-injured patients. Bone 2000; 27: 305-309.

29 Sabo D, Reiter A, Pfeil J, Gussbacher A, Niethard FU. Modification of bone quality by extreme physical stress. Bone density measurements in high-performance athletes using dual-energy X-ray absorptiometry. Z Orthop Ihre Grenzgeb 1996; 134: 25.

30 Prince RL, Price RI, Ho S. Forearm bone loss in hemiplegia: a model for the study of immobilization osteoporosis. J Bone Miner Res 1988; 3: 305-310.

31 del Puente A, Pappone N, Mandes MG, Mantova D, Scarpa R, Oriente P. Determinants of bone mineral density in immobilization: a study on hemiplegic patients. Osteoporosis Int 1996; 6: 50-54.

32 Demirbag D, Ozdemir F, Kokino S, Berkarda S. The relationship between bone mineral density and immobilization duration in hemiplegic limbs. Ann Nucl Med 2005; 19 695-700.

33 Moayyeri A, Soltani A, Khaleghnejad Tabari N, Sadatsafavi M, Hossein-Neghad A, Larijani B. Discordance in diagnosis of osteoporosis using spine and hip bone densitometry. BMC Endocr Disord 2005; 5: 1-6.

34 Kaya K, Aybay C, Ozel S, Kutay N, Gokkaya O. Evaluation of bone mineral density in patients with spinal cord injury. J Spinal Cord Med 2006; 29: 396-401.

35 Ragnarsson KT, Sell GH. Lower extremity fractures after spinal cord injury: a retrospective study. Arch Phys Med Rehabil 1981; 62: 418-423. 